\title{
Effects of age on corneal deformation by non-contact tonometry integrated with an ultra-high-speed (UHS) Scheimpflug camera
}

\author{
Efeitos da idade sobre a deformação da córnea utilizando o sistema de tonometria \\ de não contato com a câmera de Scheimpflug
}

Bruno Freitas Valbon ${ }^{1,2}$, Renato Ambrósio Jr. ${ }^{2}$, Bruno Machado Fontes ${ }^{2}$, Milton Ruiz Alves ${ }^{1}$

\begin{abstract}
Purpose: To correlate parameters derived from corneal deformation resulting from non-contact tonometry integrated with an ultra-high-speed (UHS) Scheimpflug camera (Oculus Corvis ST, Scheimpflug Technology; Wetzlar, Germany) with age in normal eyes from young patients.

Methods: Observational, retrospective study involving one eye randomly selected from study participants, totaling 89 healthy eyes. The Scheimpflug images were taken with an ultra-high-speed camera during each measurement by the corvis ST. The deformation amplitude (DA) and other parameters (e.g., pachy apex, intraocular pressure, $1^{\text {st }} \mathrm{A}$ time, highest concavity-time, $2^{\text {nd }} \mathrm{A}$ time, $1^{\text {st }} \mathrm{A}$ Length, $2^{\text {nd }}$ A Length, Wing-Dist, curvature radius highest concavity, curvature radius normal, Vin, Vout) measured by the corvis ST were correlated with age. The KolmogorovSmirnov test was applied, and Spearman's correlation test was utilized to evaluate the parameters measured by the Corvis ST and age.

Results: Mean patient age was $27.50 \pm 6.30$ years. The highest concavity-time was the only studied parameter statistically significantly correlated to age (i.e., $p=0.04$, $r s=0.18)$. All other corvis parameters were not correlated to age. This included $\mathrm{DA}(\mathrm{p}=0.319)$, intraocular pressure $(\mathrm{p}=0.854)$, pachy apex $(\mathrm{p}=0.066), 1^{\text {st }} \mathrm{A}$ time $(p=0.959), 2^{\text {nd }} A$ time $(p=0.561), 1^{\text {st }}$ Length $(0.552), 2^{\text {nd }}$ Length $(p=0.697)$, Wing-Dist $(p=0.769)$, curvature radius $\mathrm{HC}(p=0.145)$, curvature radius normal $(p=0.513)$, Vin $(p=0.980)$ and Vout $(p=0.592)$.
\end{abstract}

Conclusions: In healthy eyes, age and pressure or biomechanics as derived from the Corvis ST parameters were not associated with exception to highest concavity-time, i.e., the time from starting until the highest concavity is reached.

Keywords: Tonometry, ocular; Cornea; Biomechanics; Age factors

\section{RESUMO}

Objetivo: Correlacionar os parâmetros derivados da deformação da córnea pelo sistema de tonometria de não-contato integrado com a câmera ultra-rápida de Scheimpflug (Oculus Corvis ST, Scheimpflug Technology; Wetzlar, Germany) com a idade de pacientes jovens saudáveis.

Métodos: Estudo observacional, retrospectivo envolvendo 89 olhos de 89 pacientes. As imagens de Scheimpflug foram feitas pela câmera acoplada ao sistema de tonometria de não-contato (Corvis ST) em cada paciente e os parâmetros utilizados foram: Deformidade de amplitude (DA), paquimetria, pressão intraocular, $1^{\text {st }} \mathrm{A}$ time, tempo de concavidade máxima, $2^{\text {nd }} A$ time, $1^{\text {st }} A$ Length, $2^{\text {nd }} A$ Length, Wing-Dist, raio de curvatura de maior alcance, raio de curvatura normal, Velocidade de entrada (Vin) e de saída (Vout). Estes parâmetros foram correlacionados com a idade.

Resultados: A média de idade dos pacientes foi de 27,50 $\pm 6,30$ anos. $O$ tempo de concavidade máxima alcançada da córnea (HC-time) foio único parâmetro estudado estatisticamente significante correlacionado com a idade $(p=0,04, r s=0,18)$. O valor $p$ das correlações dos parâmetros derivados do Corvis ST e idade foram: DA $(p=0,319)$, pressão intraocular $(p=0,854)$, paquimetria $(p=0,066), 1^{\text {st }} A$ time $(p=0,959), 2^{\text {nd }} A$ time $(p=0,561), 1^{\text {st }}$ Length $(0,552), 2^{\text {nd }}$ Length $(p=0,697)$, Wing-Dist $(p=0,769)$, raio de curvatura de maior alcance $(p=0,145)$, curvature radius normal $(p=0,513)$, Vin $(p=0,980)$ e Vout $(p=0,592)$

Conclusão: Em olhos saudáveis de pacientes jovens, a idade e os parâmetros pressóricos e biomecânicos da deformação da córnea não foram associados, exceto o tempo de concavidade máxima, que é o tempo do início de aplanação até a concavidade máxima alcançada da córnea.

Descritores: Tonometria ocular; Córnea; Biomecânica; Fatores etários

\section{INTRODUCTION}

The biologic variability of healthy corneas probably results from differing amounts of collagen fibrils, glycosaminoglycans, and proteoglycans found in the stroma of various individuals $s^{(1,2)}$. Corneal stiffening may result from collagen fibril diameters increasing ${ }^{(3)}$ and interfibrillar spacings decreasing ${ }^{(4,5)}$. Age-related changes in corneal biomechanical properties have been studied and were associated with corneal stiffening and decreasing viscoelasticity ${ }^{(6)}$. Experimental ex vivo studies have demonstrated age-related changes in corneal collagen fibril properties that may contribute to an increased stiffness of the cornea with age ${ }^{(7,8)}$. In vivo endothelial specular microscopic studies by Sherrard et al. ${ }^{\left({ }^{(9)}\right.}$ have demonstrated corneal signs that indicate an increased corneal stiffness with age.
Knowledge of corneal biomechanics is essential to the understanding of the behavior of the cornea in certain corneal diseases, surgical procedures, and intraocular pressure (IOP) measurements. In 1973, some authores ${ }^{(10)}$, asserted that the viscoelastic response of an intact human cornea subjected to physiological IOP could be determined by the local deformation as measured by a flying spot micrometer. In 2004, The Ocular Response Analyzer (ORA, Reichert Inc., Depew, NY), a modified non-contact tonometer (NCT) designed to provide a more accurate measurement of IOP through the understanding of compensation for corneal properties, was the first clinical tool developed to assess the in vivo biomechanical properties of the cornea ${ }^{(11)}$. The Corvis ST (Scheimpflug Technology) is a new NCT system integrated with an ultra-high-speed (UHS) Scheimpflug camera
Funding: No specific financial support was available for this study.

Disclosure of potential conflicts of interest: B.F.Valbon, None; R.Ambrósio Jr. is consultant for Oculus; B.M.Fontes, None; M.R.Alves, None.

Correspondence address: Bruno Freitas Valbon. Av. Marechal Mascarenhas de Moraes, 2767/102 Vitória (ES) - 29052-121 - Brazil - E-mail: brunovalbon@usp.br 
that was recently introduced by Oculus (Wetzlar, Germany); it also provides corneal biomechanical and IOP information.

This study was designed to evaluate and correlate corneal response to NCT integrated with an UHS Scheimpflug camera with age in healthy corneas from young patients.

\section{METHODS}

This retrospective study population included 89 eyes from 89 healthy patients at the Instituto de Olhos Renato Ambrósio in Rio de Janeiro, Brazil, between March of 2011 and June of 2012. The research followed the tenets of the Declaration of Helsinki, and institutional review board approval (protocol 2012/10) from the Federal University of Sao Paulo, Brazil, was obtained.

Each clinical examination involved tests for visual acuity, slit-lamp microscopy of the anterior and posterior segment, Goldmann applanation tonometry (Haag-Streit, Koeniz, Switzerland), and Corvis ST measurements. Exclusion criteria included previous corneal surgery, diseases (e.g., glaucoma, uveitis, corneal ectatic disease, Fuchs' dystrophy, diabetic retinopathy, systemic collagen diseases), chronic use of topical medications, corneal scars and/or opacities, irregular astigmatisms, and refusal to sign informed consent.

The central corneal thickness (CCT) was determined by rotating Scheimpflug imaging (Pentacam, Oculus, Wetzlar, Germany).

The instrument (i.e., the Corvis ST from Oculus in Wetzlar, Germany) has an ergonomic design with an adjustable head console and chin rest. The patient can be comfortably positioned due to the proper placement of the chin and forehead. The patient is asked to focus at the central red light emitting diode (LED). A frontal view camera is mounted with a keratometer-type projection system for focusing and aligning the corneal apex. The exam is programmed for automatic release when alignment is achieved with the first Purkinje reflex of the cornea. Manual release is also possible.

The UHS Scheimpflug camera takes over 4,300 frames per second in order to monitor corneal response to a metered, collimated air pulse with symmetrical fixed profile and a fixed maximal internal pump pressure of $25 \mathrm{kPa}$. The UHS Scheimpflug camera has a blue light LED (455 nm, UV free) and horizontally covers $8.5 \mathrm{~mm}$ of a single slit. Recording measurement time is $30 \mathrm{~ms}$, which allows for the acquisition of 140 digital frames. Each image has 576 measuring points.

This imaging system permits the dynamic inspection of the actual deformation process during NCT. Advanced algorithms for edge detection of the corneal contours are applied for every frame. The recording starts with the cornea at the natural convex shape. The air pulse forces the cornea inwards (i.e., the ingoing phase) through applanation (i.e., the first or ingoing applanation) into a concavity phase until it achieves the highest concavity $(\mathrm{HC})$. An oscillation period precedes the outgoing or returning phase. The cornea undergoes a second applanation before achieving its natural shape with possible oscillation.

The timing and corresponding pressure of the air pulse at the first and second applanations and at the $\mathrm{HC}$ moments are identified. IOP is calculated based on the timing of the first applanation event. The deformation amplitude (DA) is measured as the highest displacement of the apex in the $\mathrm{HC}$ moment image. The radius of curvature at the $\mathrm{HC}$ is recorded. Applanation lengths (AL) and corneal velocities (CVel) are recorded during ingoing and outgoing phases. Corneal thickness is also calculated through the horizontal Scheimpflug image. The lowest value is displayed.

The parameters measured by the Corvis ST (Table 1) under investigation were as follows: IOP, DA, pachy apex, $1^{\text {st }} \mathrm{A}$ time, $\mathrm{HC}$-time, $2^{\text {nd }} \mathrm{A}$ time, $1^{\text {st }} \mathrm{A}$ length (max), $2^{\text {nd }} \mathrm{A}$ length ( $\left.\max \right)$, Wing-Dist, curvature radius highest curvature, curvature radius normal, Maximum Velocity-Vin and Maximum Velocity-Vout.

Statistical analysis were performed using the Bioestat version 5.0 software (Belém, PA, Brazil). Variables that were not normally distributed in all data samples were confirmed by the Kolmogorov-Smirnov test. Spearman's correlation coefficient was utilized, and $p$ values less than 0.05 were considered statistically significant (Table 2).

\section{RESULTS}

The study investigated 89 healthy eyes from 89 patients (i.e., 51 females and 38 males) with normal cornea. The single eye from each patient was randomly chosen, and the study investigated 43 right eyes and 46 left eyes (i.e., $48.31 \%$ and $51.68 \%$, respectively). The mean patient age was $27.50 \pm 6.30$ (i.e., range: 12.54 to 39.70 years). The Spearman's correlation test between CCT and IOP Corvis was statiscally significant (Figure 1).

The mean IOP as measured by the Corvis ST was $17.73 \mathrm{mmHg} \pm$ 3.81 (i.e., range: 7.00 to 32.20). Spearman's correlation test was not statistically significant (i.e., $p=0.854$, rs -0.01 ).

The mean deformation amplitude was $1.02 \mathrm{~mm} \pm 0.09$ (i.e., range: 0.78 to 1.26 ). Spearman's correlation test was not statistically significant (i.e., $p=0.319$, rs 0.09) (Figure 2).

The mean pachy apex was $522.99 \mu \mathrm{m} \pm 24.15$ (i.e., range: 463 to 605). Spearman's correlation test was not statistically significant (i.e., $\mathrm{p}=0.06$, rs 0.16) (Figure 3).

Table 1. All parameters derived from Corvis ST and their meanings

\begin{tabular}{ll}
\hline Corvis ST - clinical parameters & \multicolumn{1}{c}{ Means } \\
\hline Intraocular pressure & Is the NCT measurement based on the $1^{\text {st }}$ applanation \\
$1^{\text {st }}$ A-time & Is the time from starting until the first applanation \\
Highest Concavity-time & Time from starting until highest concavity is reached \\
$2^{\text {nd }}$ A-time & Time from starting until the second applanation \\
$1^{\text {st }}$ A length & Cord length of the first applanation \\
$2^{\text {nd }}$ A length & Cord length of the second applanation \\
Deformation amplitude & Maximum amplitude at the apex (highest concavity) \\
Wing-Dist & Distance of the two "knee's" at highest concavity (HC) \\
Curvature radius HC & Central concave curvature at HC \\
Curvature radius normal & Initial central convex curvature \\
Maximun velocity (in) - Vin & Corneal speed during the first applanation moment \\
Maximum velocity (out) - Vout & Corneal speed during the second applanation moment \\
\hline
\end{tabular}


Table 2. Age versus all parameters from Corvis ST. Spearman correlation test was utilized; value $p$ and Spearman correlation coefficient (rs)

\begin{tabular}{|c|c|c|c|c|c|c|c|c|c|c|c|c|c|}
\hline $\begin{array}{l}\text { Age } \\
\text { versus }\end{array}$ & IOP & $\begin{array}{c}\text { Deformation } \\
\text { Amplitude }\end{array}$ & $\begin{array}{l}\text { Pachy } \\
\text { apex }\end{array}$ & $\begin{array}{c}\text { Highest } \\
\text { concavity - time }\end{array}$ & $\begin{array}{c}1^{\text {st }} \\
\text { A time }\end{array}$ & $\begin{array}{c}2^{\text {nd }} \\
\text { A time }\end{array}$ & $\begin{array}{c}1^{\text {st }} \\
\text { Length }\end{array}$ & $\begin{array}{c}2^{\text {nd }} \\
\text { Length }\end{array}$ & $\begin{array}{c}\text { Wing- } \\
\text { Distance }\end{array}$ & $\begin{array}{l}\text { Curvature } \\
\text { radius HC }\end{array}$ & $\begin{array}{c}\text { Curvature } \\
\text { radius normal }\end{array}$ & Vin & Vout \\
\hline Value $p$ & 0.854 & 0.319 & 0.066 & 0.048 & 0.959 & 0.561 & 0.552 & 0.697 & 0.769 & 0.145 & 0.513 & 0.980 & 0.592 \\
\hline Rs & -0.01 & 0.09 & 0.16 & 0.18 & 0.004 & -0.06 & -0.05 & 0.03 & -0.02 & 0.13 & -0.06 & -0.002 & 0.04 \\
\hline
\end{tabular}

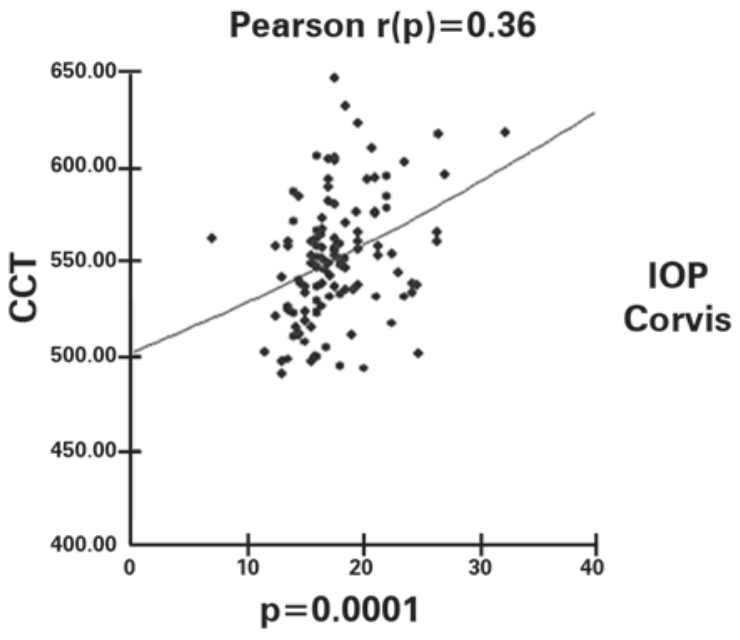

Figure 1. Correlations between CCT x IOP Corvis.

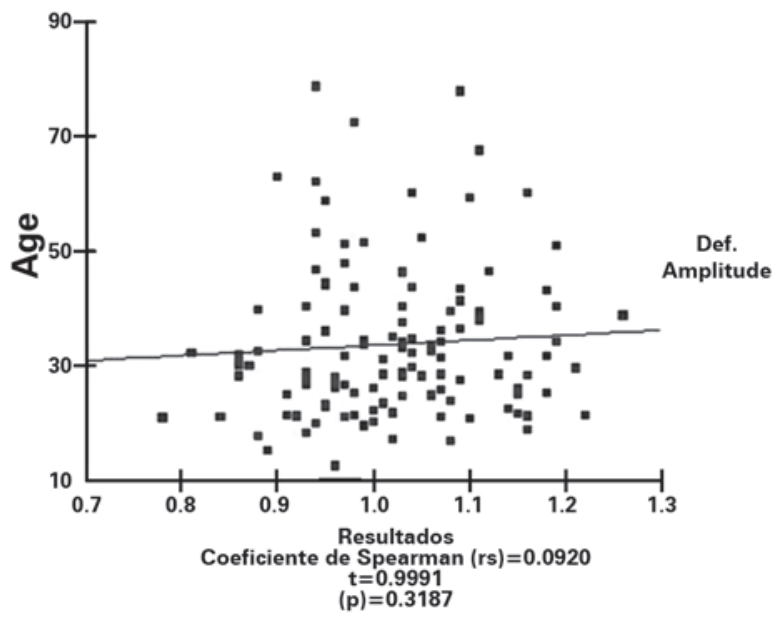

Figure 2. Correlations between Age x Deformation Amplitude.

The mean HC-time was 18.83 ms \pm 0.93 (i.e., range: 16.72 to 21.07 ). Spearman's correlation test was statistically significant ( $p=0.04$, rs 0.18 ) (Figure 4).

The mean $1^{\text {st }} \mathrm{A}$ time was $8.47 \mathrm{~ms} \pm 0.51$ (i.e., range: 6.60 to 10.40 ). Spearman's correlation test was not statistically significant $(p=0.95$; rs 0.004). The mean $2^{\text {nd }} \mathrm{A}$ time was $23.68 \mathrm{~ms} \pm 0.55$ (i.e., range: 22.06 to 24.95). Spearman's correlation test was not statistically significant $(p=0.56, r s-0.05)$.

The mean $1^{\text {st }} \mathrm{A}$ length (max) was $2.09 \mathrm{~mm} \pm 0.38$ (i.e., range: 1.20 to 3.10). Spearman's correlation test was not statistically significant (i.e., $p=0.55$, rs -0.05 ). The mean $2^{\text {nd }} A$ length ( $\max$ ) was $2.37 \mathrm{~mm} \pm$ 0.48 (i.e., range: 1.33 to 4.12 ). Spearman's correlation test was not statistically significant ( $p=0.69$, rs 0.03 ).

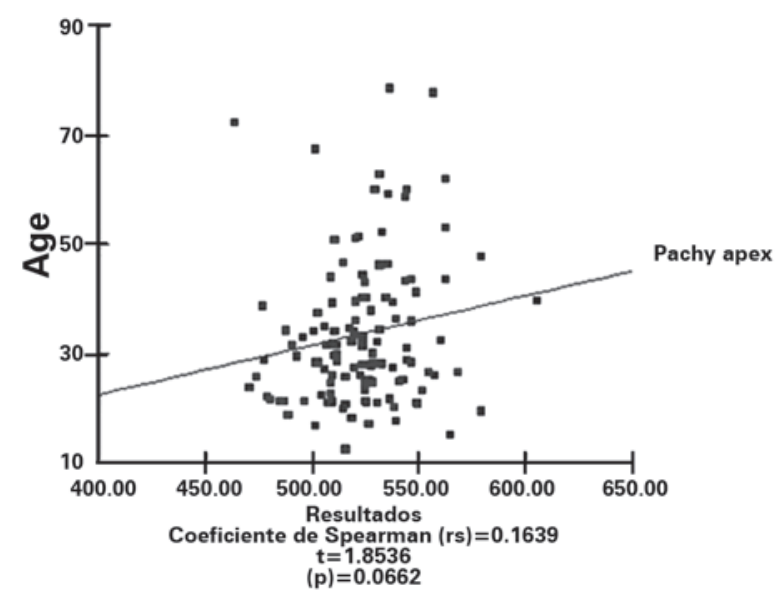

Figure 3. Correlations between Age x Pachy apex.

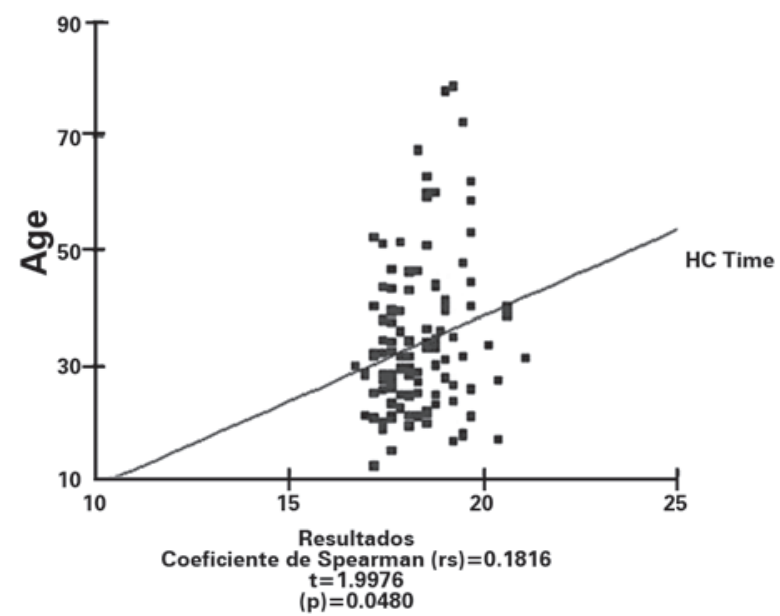

Figure 4. Correlations between Age x Highest Concavity time.

The mean Wing-Dist was $4.77 \mathrm{~mm} \pm 0.28$ (i.e., range: 3.98 to 5.24). Spearman's correlation test was not statistically significant (i.e., $\mathrm{p}=0.76, \mathrm{rs}-0.02)$.

The mean curvature radius highest concavity was $11.59 \mathrm{~mm} \pm$ 2.57 (i.e., range: 7.20 to 20.76). Spearman's correlation test was not statistically significant ( $p=0.14$, rs 0.13 ) (Figure 5).

The mean curvature radius normal was $7.63 \mathrm{~mm} \pm 0.91$ (i.e., range: 6.82 to 13.77$)$. Spearman's correlation test was not statistically significant (i.e., $p=0.51$, $r s-0.06$ ).

The mean Vin was $0.21 \mathrm{~m} / \mathrm{s} \pm 0.05$ (i.e., range: 0.15 to 0.72 ). Spearman's correlation test was not statistically significant (i.e., $p=0.98$; rs - 0.002). The mean Vout was $-0.32 \mathrm{~m} / \mathrm{s} \pm 0.07$ (i.e., range: -0.75 to -0.19 ). Spearman's correlation test was not statistically significant (i.e., $p=0.59$, rs 0.04 ). 


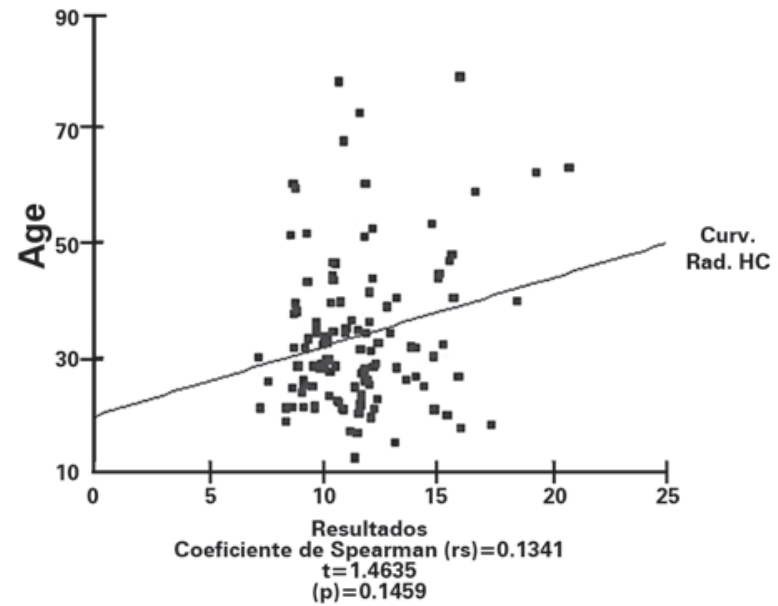

Figure 5. Correlations between Age x Curvature Radius highest concavity.

\section{DISCUSSION}

The cornea is a complex viscoelastic tissue with both viscous and elastic properties ${ }^{(12)}$.Corneal biomechanics involve thickness, hydration, elasticity, viscosity, and other unrevealed factors ${ }^{(13)}$, and its behavior is mostly controlled by the stroma ${ }^{(14)}$, which composes $90 \%$ of the total corneal thickness and presents higher mechanical stiffness than the other corneal layers ${ }^{(15)}$. This stromal microstructure is known to change with aging ${ }^{(16)}$.

Several studies showed the relationship between corneal biomechanics as measured by ORA (i.e., corneal hysteresis [CH] and corneal resistance factor $[\mathrm{CRF}]$ ) and age. Other authors ${ }^{(17)}$ demonstrated the inverse association between age and corneal biomechanics metrics, and the mean $\mathrm{CH}$ and the mean patient age were 10.17 and 46.5 years, respectively. Kirwan et al. ${ }^{(18)}$, showed that in healthy children the mean $\mathrm{CH}$ was 12.5, which was not correlated to age. Other studies $^{(19,20)}$, did not identify a strong association between $\mathrm{CH}$ and age or CRF and age and observed a negative association between corneal viscoelastic properties with advancing age, which may be further evidence of an increase in the cross-linkage of collagen fibrils within the cornea, thereby making the cornea a stiffer and less viscoelastic structure. This indicates that the biomechanical viscoelasticity of the cornea decreases with age.

In our study, we utilized an innovative imaging system that provides in vivo biomechanical information and avoids the limitations of previous in vivo and in vitro techniques. The retrieved data and deformations obtained by the Corvis ST provide information related to the biomechanical properties of the tissue, including elasticity and viscoelasticity. Consequently, this technique shows enormous potential as a research and clinical tool used to retrieve in vivo biomechanical properties of the cornea ${ }^{(21)}$.

The only parameter measured by the Corvis ST that was statistically significantly associated with age was $\mathrm{HC}$-time, i.e., the time from starting until $\mathrm{HC}$ is reached, and this association was presented as a positive linear correlation ( $r$ 0.18). The pachy apex (i.e., the corneal thickness) and other parameters, such as the DA and the curvature radius highest concavity, were not statistically significantly associated with age, by they also demonstrated a positive linear correlation with age in young patients (Figures 3, 2, and 4, respectively).

\section{CONCLUSION}

We believe that the positive association between age and HC-time can be explained as an increase in the cross-linkage of collagen fibrils within the cornea, which results in a less viscoelastic structure in young patients. Further studies with this new technology are needed to corroborate our findings and to expand the knowledge base of corneal biomechanical properties.

\section{REFERENCES}

1. Boote $C$, Hayes $S$, Abahussin M, Meek KM. Mapping collagen organization in the human cornea: Left and right eyes are structurally distinct. Invest Ophthalmol Vis Sci [Internet].2006[cited 2010 Jun 21];47(3):901-8.Available from: http://www.iovs.org/ content/47/3/901.long

2. Roberts C. The cornea is not a piece of plastic. J Refract Surg. 2000;16(4):407-13. Comment in: J Refract Surg. 2001;17(1):76-7; author reply 77-8. J Refract Surg. 2001;17(1): 76; author reply 77-8.

3. Daxer A, Misof K, Grabner B, Ettl A, Fratzl P. Collagen fibrils in the human corneal stroma: structure and aging. Invest Ophthalmol Vis Sci [Internet]. 1998 [cited 2010 Jun 21];39(3):644-8.Available from: http://www.iovs.org/content/39/3/644.long

4. Malik NS, Moss SJ, Ahmed N, Furth AJ, Wall RS, Meek KM. Ageing of the human corneal stroma: structural and biochemical changes. Biochim Biophys Acta. 1992; 1138(3):222-8

5. Kanai A, Kaufman HE. Electron microscopic studies of corneal stroma: aging changes of collagen fibers. Ann Ophthalmol. 1973;5(3):285-7.

6. Elsheikh A, Geraghty B, Rama P, Campanelli M, Meek KM. Characterization of age-related variation in corneal biomechanical properties. J R Soc Interface [Internet]. 2010 [cited 2012 Apr 21];7(51):1475-85. Available from: http://rsif.royalsocietypublishing. org/content/7/51/1475.long

7. Daxer A, Misof K, Grabner B, Ettl A, Fratzl P. Collagen fibrils in the human corneal stroma: structure and aging. Invest Ophthalmol Vis Sci [Internet]. 1998[cited 20; 39(3):644-8. Available from: http://www.iovs.org/content/39/3/644.long

8. Malik NS, Moss SJ, Ahmed N, Furth AJ, Wall RS, Meek KM. Ageing of the human corneal stroma: structural and biochemical changes. Biochim Biophys Acta. 1992;1138(3):222-8

9. Sherrard ES, Novakovic P, Speedwell L. Age-related changes of the corneal endothelium and stroma as seen in vivo by specular microscopy. Eye (Lond). 1987; 1(Pt2):197-203.

10. Kobayashi AS, Staberg LG, Schlegel WA.Viscoelastic properties of human cornea. Exp Mech. 1973;12:497-503.

11. Luce DA. Determining in vivo biomechanical properties of the cornea with an ocular response analyzer. J Cataract Refract Surg. 2005;31(1):156-62.

12. Brown KE, Congdon NG. Corneal structure and biomechanics: impact on the diagnosis and management of glaucoma. Curr Opin Ophthalmol. 2006;17(4):338-43.

13. Dupps WJ, Wilson SE. Biomechanics and wound healing in the cornea. Exp Eye Res. 2006;83(4):709-20.

14. Boyce BL, Grazier JM, Jones RE, Nguyen TD. Full-field deformation of bovine cornea under constrained inflation conditions. Biomaterials. 2008;29(28):3896-904.

15. Elsheikh A, Alhasso D, Rama P. Assessment of the epithelium's contribution to corneal biomechanics. Exp Eye Res. 2008;86(2):445-51.

16. Meek KM, Leonard DW. Ultrastructure of the corneal stroma: a comparative study Biophys J. 1993:64(1):273-80.

17. Fontes BM, Ambrosio R Jr, Alonso RS, Jardim D, Velarde GC, Nose W. Corneal biomechanical metrics in eyes with refraction of -19.00 to $+9.00 \mathrm{D}$ in healthy brazilian patients. J Refract Surg. 2008;24(9):941-5.

18. Kirwan C, O'Keefe M, Lanigan B. Corneal hysteresis and intraocular pressure measurement in children using the Reichert ocular response analyzer. Am J Ophthalmol. 2006;142(6):990-2. Erratum in: Am J Ophthalmol. 2007;144(4):642.

19. Touboul D, Roberts C, Kerautret J, Garra C, Maurice-Tison S, Saubusse E, et al. Correlation between corneal hysteresis intraocular pressure, and corneal central pachymetry. J Cataract Refract Surg. 2008;34(4):616-22.

20. Kotecha A, Elsheikh A, Roberts CR, Zhu HG, Garway-Heath DF. Corneal thicknessand age-related biomechanical properties of the cornea measured with the ocular response analyzer. Invest Ophthalmol Vis Sci [Internet]. 2006[cited 2012 May 21]; 47(12):5337-47. Available from: http://www.iovs.org/content/47/12/5337.long

21. Ambrósio R Jr., Ramos I, Luz A, Faria FC, Steinmueller A, Krug M, et al. Dynamic ultrahigh-speed Scheimpflug imaging for assessing corneal biomechanical properties. Rev Bras Oftalmol. 2013;72(2):99-102. 